\section{(6) OPEN ACCESS}

\title{
Research support for effective state and community tobacco control programme response to electronic nicotine delivery systems
}

\author{
Carol L Schmitt, ${ }^{1}$ Youn Ok Lee, ${ }^{2}$ Laurel E Curry, ${ }^{1}$ Matthew C Farrelly, ${ }^{2}$ Todd Rogers ${ }^{3}$
}

${ }^{1}$ Public Health Research Division, RTI International, Washington, DC, USA

${ }^{2}$ Public Health Research Division, RTI International, Research Triangle Park, North Carolina, USA

${ }^{3}$ Public Health Research Division, RTI International, San Francisco, California, USA

\section{Correspondence to} Dr Youn Ok Lee, RTI International, Public Health Research Division, 3040 E. Cornwallis Road, P.O. Box 12194, Research Triangle Park, NC 27709, USA:

younlee@rti.org

Received 26 November 2013 Revised 12 May 2014 Accepted 13 May 2014

\begin{abstract}
Objective To identify unmet research needs of state and community tobacco control practitioners pertaining to electronic nicotine delivery systems (ENDS or ecigarettes) that would inform policy and practice efforts at the state and community levels, and to describe ENDS-related research and dissemination activities of the National Cancer Institute-funded State and Community Tobacco Control Research Initiative.

Methods To determine specific research gaps relevant to state and community tobacco control practice, we analysed survey data collected from tobacco control programmes (TCPs) in all 50 US states and the District of Columbia ( $\mathrm{N}=51)$. Survey items covered a range of ENDS issues: direct harm to users, harm of secondhand vapour, cessation, flavours, constituents and youth access.
\end{abstract}

Results There is no ENDS topic on which a majority of state TCP managers feel very informed. They feel least informed about harms of secondhand vapour while also reporting that this information is among the most important for their programme. A majority $(\mathrm{N}=31)$ of respondents indicated needs for research on the implications of ENDS products for existing policies. Conclusions TCP managers report that ENDS research is highly important for practice and need research-based information to inform decision making around the inclusion of ENDS in existing tobacco control policies. For optimal relevance to state and community TCPs, research on ENDS should prioritise study of the health effects of ENDS use and secondhand exposure to ENDS vapour in the context of existing tobacco control policies.

\section{BACKGROUND}

Electronic nicotine delivery systems (ENDS), also referred to as electronic cigarettes or e-cigarettes, were first identified in the health literature in 2007. ${ }^{1}$ Since then, ENDS sales have doubled every year, reaching annual sales of $\$ 1$ billion in August 2013. ${ }^{2}$ From 2010 to 2011, adult awareness of ENDS increased from about $40.9 \%$ to $57.9 \%$, and ever use increased from about $3.3 \%$ to $6.2 \%{ }^{3}$

Many states have well-established tobacco control policies addressing price, exposure to secondhand smoke and marketing related to combustible tobacco. However, although research on ENDS has rapidly increased since their introduction to the US market, much of this work is in the early stages. ${ }^{4}$ As a result, there is relatively little ENDS research to guide public health programmes and legislators in these areas as they relate to ENDS. For example, several states, including Arkansas, New Jersey, North Dakota and Utah, have included ENDS in existing indoor smoking bans; while others, such as Alabama and North Carolina, have passed measures exempting them from such bans. ${ }^{4}$

We surveyed state tobacco control programme (TCP) managers to identify what they know about ENDS and the information about ENDS that they most need for policy and practice efforts at the state and community levels. The aim of this study was to gather and synthesise data on the current level of understanding and salience of key ENDS issues among state TCP leaders, which may inform research in this area. We specifically hypothesised that the level of understanding of ENDS issues would be relatively low, even among this sample of expert tobacco control practitioners, although issue salience would be very high. These expressed needs can inform current and future research in this area, including research that can be conducted as part of the State and Community Tobacco Control Research Initiative, whose project findings are the focus of this special issue. In addition, our findings will help prioritise translation and dissemination of information to best meet practice needs.

\section{METHODS}

Participants were the TCP managers in all 50 states and the District of Columbia. Programme managers and their contact information were identified and obtained from the Tobacco Control Network website (http://www.ttac.org/TCN/). The survey was conducted in October and November 2013.

\section{Materials}

The survey consisted of 16 items. Participants were asked to rate how well-informed they were about six e-cigarette topics and how important knowing this information (about each e-cigarette topic) was for their programme on a scale ranging from 1 (not at all) to 3 (very). The six topics were as follows: health effects of e-cigarettes on users, effects of secondhand e-cigarette vapour on non-users, youth access to e-cigarettes, effects of e-cigarette use on smoking cessation, constituents of e-cigarette vapour, and the inclusion of fruit and candy flavours in e-cigarettes. They were then asked to rate their level of concern about youth and adult e-cigarette use in their state on a scale ranging from 1 (not at all concerned) to 3 (very concerned). Participants were encouraged to elaborate on their responses to these 16 questions, and interviewers recorded those comments verbatim. The final two questions were open-ended. Participants were asked to describe any information about e-cigarettes that 
they considered important to their programme that was not included in the survey. They were also asked to name any professional training opportunities they had participated in during the past 30 days.

\section{PROCEDURE}

The list of 51 TCP managers was divided among four research team members. A lead email letter was sent to each tobacco control manager by the assigned interviewer. The lead letter stated the purpose of the study, noted that the survey would take less than $5 \mathrm{~min}$ and asked recipients to provide a date and time they or their representative would be available to complete the survey. The majority of interviews were scheduled as a result of one email. In approximately a third of the cases, a second or third request was sent before the interview was scheduled. Participants were then contacted at the agreed-upon time by telephone, completed informed consent and subsequently completed the interview. These data were collected according to protocol approved by the RTI Institutional Review Board.

\section{RESULTS}

A representative from the TCPs of all 50 states and the District of Columbia completed the survey, a $100 \%$ response rate. Before analysing the quantitative responses, we reviewed the open-text comments associated with those items. The lack of available research on ENDS was mentioned by 16 participants; in 5 cases, participants rated themselves as 'very informed' on some topics, and commented that they were familiar with all the available research. In 11 cases, participants rated themselves as 'not at all' or 'somewhat' informed and commented that there was not much research available to know. In the cases where participants rated themselves as 'very informed' and qualified that there is not much available to know, we recoded responses to the mid-range 'somewhat informed.' We subsequently summarised participant levels of knowledge for each of the six topic areas.

Two researchers independently coded participant responses to the question that asked them to identify any information about ENDS not included in the survey. The resulting themes from each review were compared and discussed until consensus was reached and a final list of themes was agreed upon.

Figure 1 summarises participants' level of knowledge about all six topics. As this figure shows, more than half of respondents report being not at all informed about the effects of secondhand ENDS vapour on non-users. Almost a third of respondents feel not at all informed about chemicals and other constituents in e-cigarette vapour. There is no ENDS topic for which a majority of state TCP practitioners feel very informed. Youth access had the greatest proportion of respondents choosing 'very informed.'

Figure 2 summarises participant views on how important knowing information about these six topics is to their programme. The vast majority of respondents (82-94\%) rated the importance of knowing information about all six of the ENDS topics 'very important' for their respective states or programmes. No topic received a rating of 'not at all important.' The topic 'Fruit and candy flavoured ENDS' was rated very important to know about by the fewest practitioners (82\%), while health effects of ENDS on users and the effects of secondhand vapour on non-users were rated very important by most respondents.

State tobacco control practitioners report that they are very concerned about youth (80.4\%) and adult (76.5\%) ENDS use in their state. No respondents to the survey reported that they were 'not at all concerned,' while a minority reported being 'somewhat concerned' about youth (19.6\%) and adult (23.5\%) ENDS use in their own state.

In response to the open-ended question asking practitioners if any other ENDS-related topics were important for their work in states, respondents reported a variety of answers. Many $(n=24)$ reiterated topics already covered in the survey. Other research priority areas mentioned by respondents are listed in table 1 .

Policy was mentioned the most frequently, by 31 states. Specifically, state practitioners wanted to know how to address ENDS in smoke-free air laws, how to treat them in terms of taxation, retail availability and youth access. In addition, they desire Food and Drug Administration (FDA) guidance on ENDS. The second most frequent priority area mentioned that was not covered by the close-ended survey questions was ENDS uptake. State practitioners wanted to know about the addictiveness of these products, their initiation and use with other tobacco products and whether non-smokers use them. Various other topic areas were touched upon, such as ENDS use as harm reduction, renormalising of smoking and public messaging about ENDS. See table 1 for priority areas listed by state TCP practitioners.
Figure 1 State tobacco control programme knowledge about electronic nicotine delivery systems (ENDS) issues $(\mathrm{N}=51)$.

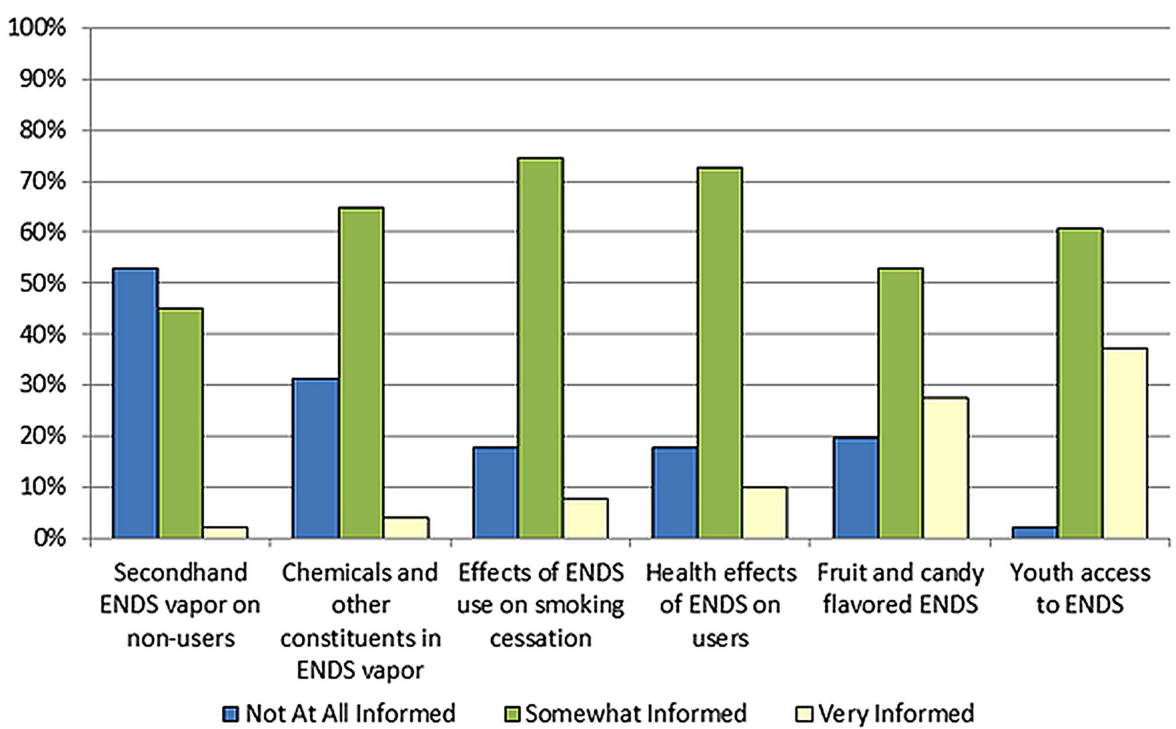




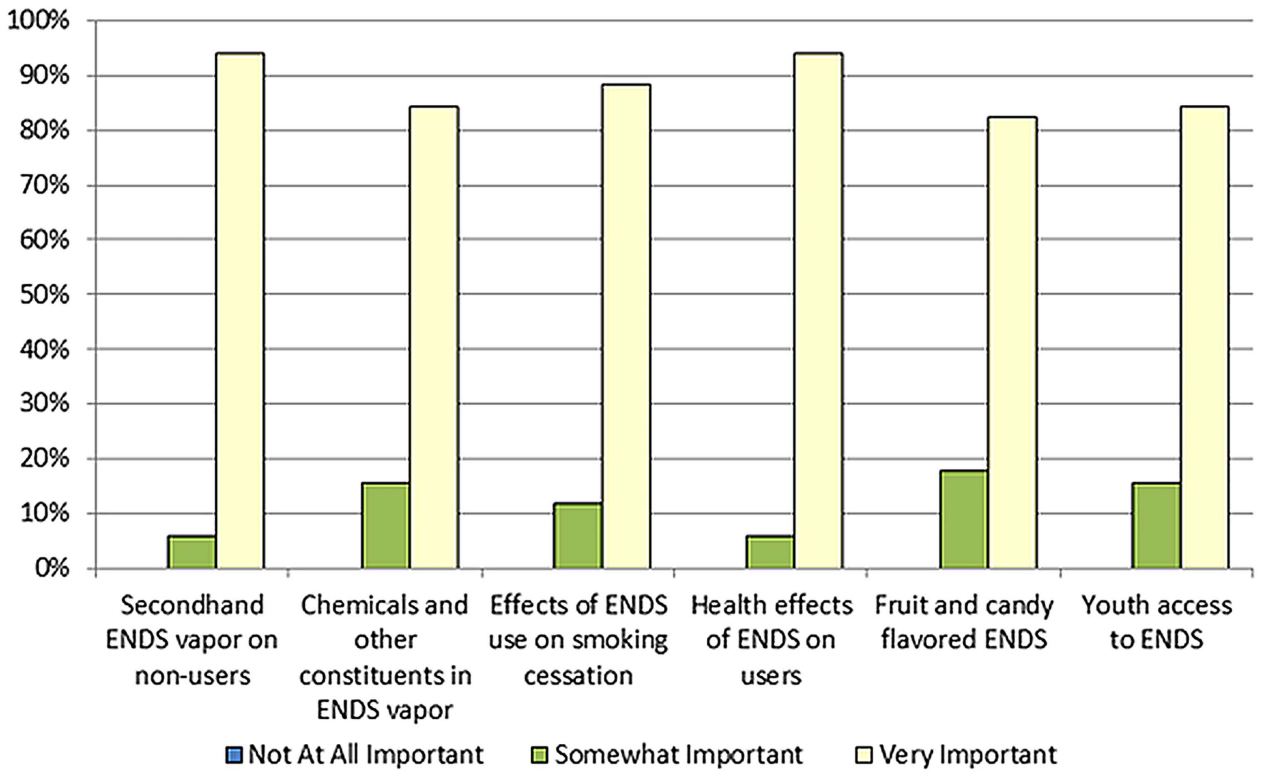

Figure 2 Importance of electronic nicotine delivery systems (ENDS) issues reported by state tobacco control programmes ( $\mathrm{N}=51$ ).

\section{DISCUSSION}

Consistent with our hypothesis, the expert tobacco control practitioners in this study reported a low level of understanding about most ENDS issues. The 51 state TCP managers report being the least informed on the effects of secondhand aerosol on non-ENDS users, the constituents or make-up of ENDS vapour, the effects of ENDS use on cessation and the health effects of ENDS use on users. These knowledge gaps are consistent with gaps in the extant ENDS research, which at the time of our study focused primarily on the increasing prevalence of ENDS use and consumer motivations and perceptions about these products. ${ }^{4}$ A review of the ENDS literature published subsequent to our study documented research conducted to date on the constituents of ENDS vapour, the effects of ENDS use on cessation and the health effects of ENDS use on users, ${ }^{5}$ but not on the effects of secondhand aerosol on non-users. Although the review concludes that the evidence is sufficient to support policy interventions, the authors cite the need for more research in all of these areas.

Also consistent with our hypothesis, ENDS issues were of high salience to participants. They rated health effects of ENDS on users and non-users as most important, followed by the effects of ENDS use on cessation. These topics are most relevant to the current policy issues these practitioners face, including adding ENDS to smoke-free indoor air laws, and determining whether ENDS have a role in cessation policies. For example, evidence about the impact of secondhand ENDS vapour on non-users can be used to support the rationale for including ENDS in smoke-free

Table 1 Electronic nicotine delivery systems (ENDS) research priority areas reported by District of Columbia and US State tobacco control programmes $(\mathrm{N}=51)$

\begin{tabular}{|c|c|c|}
\hline Priority area & $\begin{array}{l}\text { Number of states } \\
\text { mentioning }\end{array}$ & Example \\
\hline Policy & 31 & How to address ENDS in smoke-free, tax, retail, youth access and insurance policy; desire for FDA guidance \\
\hline ENDS uptake & 9 & $\begin{array}{l}\text { ENDS as 'gateway' to other tobacco products, nicotine addiction; initiation of conventional tobacco through } \\
\text { ENDS; dual use; non-smoker uptake }\end{array}$ \\
\hline Marketing of ENDS & 8 & $\begin{array}{l}\text { Display of ENDS in stores; impact of television, radio, online, print advertising on uptake; how, where and how } \\
\text { much ENDS marketing; cessation messaging in advertising; 'vape shops' opening in places with weak } \\
\text { smoke-free laws; marketing regulation }\end{array}$ \\
\hline Harm reduction & 6 & $\begin{array}{l}\text { Rift in public health community regarding harm reduction; splits the research and practice arms of tobacco } \\
\text { control; role of ENDS in harm reduction }\end{array}$ \\
\hline $\begin{array}{l}\text { Messaging to the public about } \\
\text { ENDS }\end{array}$ & 6 & $\begin{array}{l}\text { Tobacco control community needs to agree upon a common message before community with the public; } \\
\text { what are best practices; effective messaging strategies; how to communicate risks of ENDS to public; "the } \\
\text { correct public health way to message about [ENDS]" }\end{array}$ \\
\hline Definition of ENDS products & 5 & $\begin{array}{l}\text { Are ENDS tobacco products?; legal guidelines for ENDS and legislation; definitions of products covered by } \\
\text { smoke-free laws; how to define? }\end{array}$ \\
\hline Normalisation of smoking & 4 & $\begin{array}{l}\text { Impact of normalisation of ENDS smoking on youth initiation; "de-normalization of } 25 \text { years of tobacco } \\
\text { control"; modelling behaviour for youth; smoking renormalised through ENDS }\end{array}$ \\
\hline $\begin{array}{l}\text { ENDS use to administer other } \\
\text { drugs }\end{array}$ & 3 & $\begin{array}{l}\text { Devices being used for recreational use of marijuana; reports of ENDS used to administer heroin and pot; } \\
\text { cannabinoids, other narcotics in e-cigarettes }\end{array}$ \\
\hline ENDS industry activity & 1 & Influence of industry on ENDS definition for policy purposes \\
\hline $\begin{array}{l}\text { Collaboration between states } \\
\text { and researchers }\end{array}$ & 1 & "[we are] eager to collaborate, well-funded, and have data collection opportunities to... work with researchers" \\
\hline
\end{tabular}


air laws. In fact, 60\% of respondents brought up concerns and questions about policy implications of ENDS products and the need for more information on these topics to inform policy.

The studies published in this supplemental issue of Tobacco Control illustrate a range of research projects supported by the State and Community Tobacco Control initiative that are responsive to some of the needs expressed by tobacco control practitioners as they make decisions about policies and practices related to the use of ENDS. Several studies have implications for youth access, smoke-free air and price policies for ENDS. Other studies provide valuable insights on the marketing and availability of ENDS, which will in turn help practitioners develop tobacco control messages to counter their use. Continued research is needed so that policy makers have the information they need to regulate the quickly evolving marketplace for e-cigarettes and other vapour products. The findings reported here can help inform the scientific community about

\section{What this paper adds}

- There is no electronic nicotine delivery systems (ENDS) topic on which a majority of state tobacco control programs (TCPs) feels very informed.

- TCP managers feel least informed about harms of secondhand vapour while also reporting that this information is among the most important for their programme.

- TCP managers report that ENDS research is highly important for practice and need information to inform decision making around the inclusion of ENDS in existing tobacco control policies.

- For optimal relevance to state and community TCPs research on ENDS should prioritise study of the health effects of ENDS in the context of existing tobacco control policies. the kind of research needs states and communities need to face the challenges posed by the introduction of these new products.

Acknowledgements The authors would like to acknowledge Heather Hansen, Joshua Goetz and Christina Villella for their assistance with data collection and administration related to this study. This research was supported by the National Cancer Institute under the State and Community Tobacco Control Initiative, grant number U01/CA154241, Research Triangle Institute; Matthew Farrelly, Principal Investigator.

Contributors CLS designed the study, drafted and tested the survey instrument, outlined the first draft of the manuscript, and revised subsequent drafts of the manuscript. YOL drafted the background and methods and contributed to editing, data collection, and data analysis. LEC drafted the results and discussion and contributed to editing, data collection, and analysis. MCF contributed to the conceptualisation. TR contributed to the conceptualisation, data collection and editing.

Competing interests None.

Ethics approval RTI IRB.

Provenance and peer review Not commissioned; externally peer reviewed.

Open Access This is an Open Access article distributed in accordance with the Creative Commons Attribution Non Commercial (CC BY-NC 3.0) license, which permits others to distribute, remix, adapt, build upon this work non-commercially, and license their derivative works on different terms, provided the original work is properly cited and the use is non-commercial. See: http://creativecommons.org/ licenses/by-nc/3.0/

\section{REFERENCES}

1 Corey C WB, Johnson SE, Apelberg BJ, et al. Notes from the field: electronic cigarette use among middle and high school students-United States, 2011-2012. MMWR Morb Mortal Wkly Rep 2013;62:729-30.

2 Lee S, Grana RA, Glantz SA. Electronic cigarette use among Korean adolescents: a cross-sectional study of market penetration, dual use, and relationship to quit attempts and former smoking. J Adolesc Health 2013. Published Online First: pii:S1054-139X(13)00748-9. doi: 10.1016/j.jadohealth.2013.11.003

3 King BA, Alam S, Promoff G, et al. Awareness and ever use of electronic cigarettes among U.S. adults, 2010-2011. Nicotine Tob Res 2013;15:1623-7.

4 Pepper JK, Brewer NT. Electronic nicotine delivery system (electronic cigarette) awareness, use, reactions and beliefs: a systematic review. Tob Contro/ 2013. Published Online First: 22 November 2013: doi: 10.1136/tobaccocontrol-2013-051122

5 Grana R, Benowitz N, Glantz SA. Background Paper on E-cigarettes (Electronic Nicotine Delivery Systems). Center for Tobacco Control Research and Education, University of California, San Francisco, 2013. Prepared for World Health Organization Tobacco Free Initiative. 